\title{
Maija Lassila \\ FILMING LAYERS OF TIME IN AN ENDANGERED ECOSYSTEM
}

Sakatti (2017)—Film by Maija Lassila S(directing, filming, sound) with Petri Luukkainen (editing, sound) and Joona Toivanen (music). Produced by Unifilm Oy.

We filmed the short film Sakatti in the protected 6,595 ha Viiankiaapa peatland in Arctic Finland, where the British Anglo American company is conducting extensive mineral exploration. The company's aim is to construct an underground mine in the peatland, where Europe's richest copper deposit of recent decades is estimated to be located. Without a dialogue, a narrative voice, or a clear human protagonist, the 6 minute long film focuses particularly on the more-than-human, ground level, and underwater worlds of the wet mire, as well as following reindeer and their herders and geologists working in the peatland. This text focuses on the special issue's topic of time and temporality through a reflection of the element of time in the making of Sakatti. Can filmmaking, during the time of ecological crisis, grasp or make more understandable the almost incomprehensible pace and scale of the ecological collapse that is taking place all around us? And this in a time when people haven't yet even begun to completely understand the complexities of ecological wholes and our own dependency as part of them.
As I have described in an earlier text (Lassila in review for Visual Studies), filming was a method in my fieldwork. I used the camera to approach the peatland intuitively and experimentally. I felt that the otherwise traditional ethnographic research I was conducting on the mining project, with its focus on the human and its textual emphasis, did not suffice to approach the peatland as a more-than-human environment. The starting point for filming was to explore different ways of seeing, experiencing, and engaging with the peatland and its living beings more intimately and actively in the present moment. Filming was most of all an attempt to go beyond words in the context of fieldwork. As Walter Benjamin (1969 [1936]: 15-16) argues, a world opens to the film camera in a different form than to the naked eye. The camera enlarges, slows down as well as accelerates time, and extends our perceptions of reality. Through the camera lens a different kind of observance was possible than just, for example, writing down field notes.

Filming in the peatland took place against our awareness of the inevitability of the passing of time towards the peatland's unknown but certain transformation somewhere in the future. Thus, although perhaps more unconsciously, we also wanted to record a place that someday

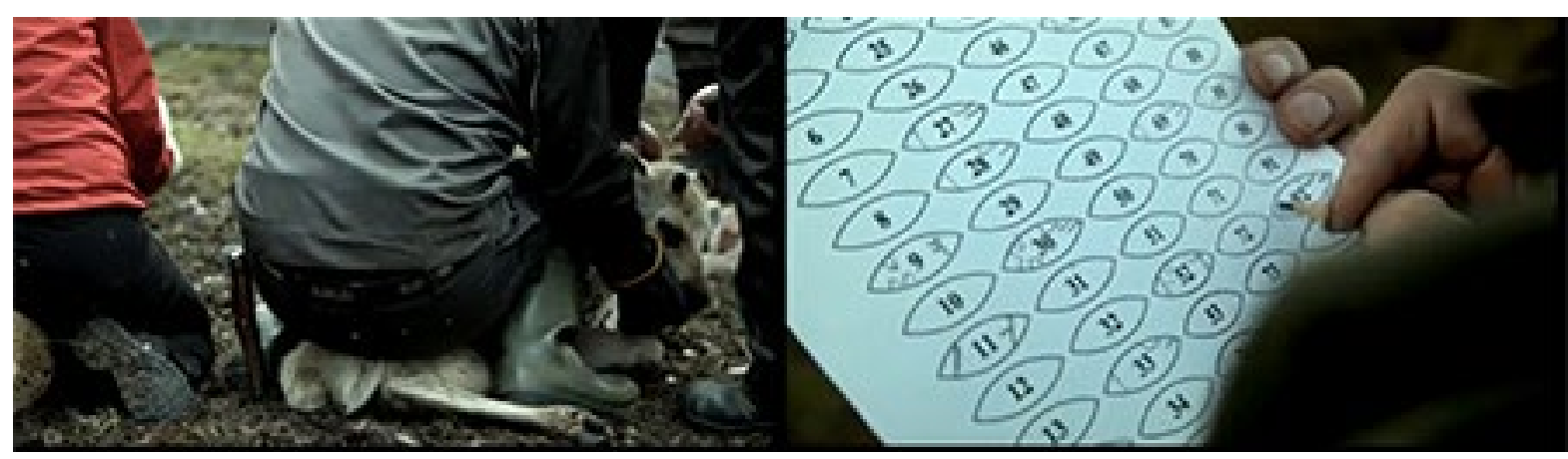


would not exist anymore. Our experience of time was formed through several layers: with the sense of the primeval peatland's total transformation in the future, the experience of passing of time in the mire when filming (for example, with the changing of light), and the acknowledgment of other living beings that we encountered in the mire and the consideration of their own time-frames. Yet another level to the experience of time was the constant awareness of what lay underneath our feetgeological formations of minerals originating from millions of years before, now perceived as valuable by the human civilization. We had the impression that the mining project was advanced determinedly by the company and the municipality. An anticipation of future prosperity around the mining project seemed to obscure the mire's miraculous capacity to accumulate a profusion of life, another type of affluence that opened before us every day.

In an era of unforeseen ecological crisis and extinction, a feeling of hopelessness prevails. Among individuals and communities the scale of environmental harm caused by corporations and allowed by the state may lead to 'politics of resignation', where people feel disempowered (Benson and Kirsch 2010: 460). Through art we can develop narratives and bring forth politically meaningful alternatives for existence where, following the Zapatista peace declaration, 'many worlds fit' (see Blaser and De la Cadena 2018: 1). This includes those worlds that do not have human voice. Rutsky (2007: 22) analyses how in Benjamin's theory of the history and reproducibility of the artwork, the sphere of the cinematic time appears as a political mode for thinking otherwise and for disrupting and dispersing the bourgeois linear narrative of history. As Benjamin (1969 [1935]: 16) writes, the camera that molds and makes its own time allows for 'unconscious optics' to become visible. Against the demand for a constant, linear progress inherent in the extractive, capitalist modernity, the cinematic form gives possibilities for finding oneself amidst other temporalities. A good experiment of this is The Golden Snail Opera by Tsai and others (2016). It is a video work with a performance-oriented text, with its aim to show and make one hear various contrasting ontologies and multispecies voices and realities at once, those of the Taiwanese golden snails and their friendly, observant farmers with their complex histories. The film/ text develops a thought that humans, whether scientists or farmers, do not explore the world alone but in relation to other observant and explorative beings (2016: 536). A film has the ability to stand as evidence to these assemblages, in contrast to a singular time supported by the modernist, extractivist ontology.

The final decision to compile a film from all of the material filmed during fieldwork formed only later and when we were already back in Helsinki. When we had decided that we would want to show the material and share

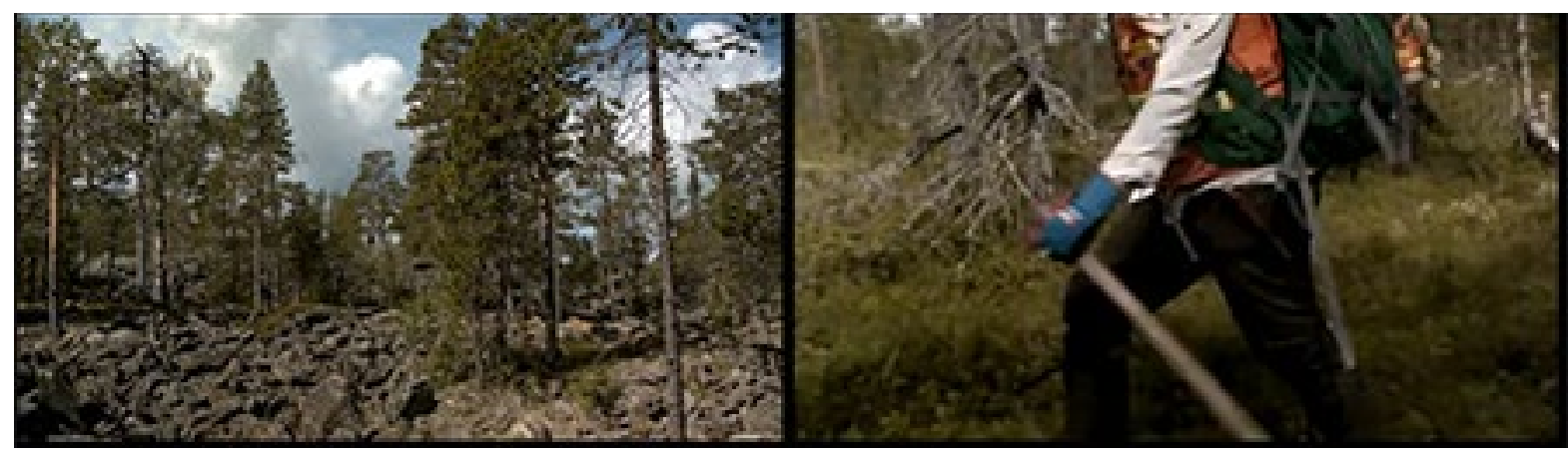


our experience with other people in a cinematic form, we edited the material into a split screen and made conscious choices of juxtaposing or highlighting the simultaneous human/animal/ inorganic worlds of the mire. The split screen served our own observations of the peatland's radically contrasting present and future trajectories. It also allowed us to abstain from a clear chronological narrative and instead leave space for lingering in the images. In the sound, we accentuated the buzzing of the mosquitoes, constant companions to our days in the mire. The film has been screened in various settings. From an audience and time experience perspective it makes a difference whether the film is set up as a looping video on a big gallery wall, where it can be touched and approached, or whether it is watched on a cinema screen in a dark theatre or as a smaller projection, both in screening events with clear beginning and ending times. In my experience, a projection that is physically close and enlarged to the viewer gives freedom for a more intimate interplay between the viewer and the film. When walking in a larger space, where the film is shown as a continuous loop, the viewer can define when to begin and stop watching, when to walk away, and when to come close. This disrupts the film's possible narrative line even more.

To conclude, how to show through film a socioecological context, where nothing has transformed yet but will do so in the future? Rather than a one-time environmental catastrophe, how to get hold of a steadily proceeding change that is tied to centuries of global exploitation? It is of course different to write about the film or see the film afterwards than to be in the moment of filming, in the peatland. The filming that started as an intuitive method in an ethnographic fieldwork became an important means to think and encounter the loss of worlds and an ecological system, of the time spans of individual lives, whether human or more-than-human, and of the possibility for a shared time that film creates. The film extended our experience of a shared time with other beings and made possible the sharing of that time with viewers. There is no common language with other beings who disappear from the way of intensifying exploitation, nor is there a total comprehension of our interdependencies with them. Yet, with methods that go beyond words we can sensitize ourselves, hopefully more and more in the future, towards other types of realities and possibilities for living.

\section{REFERENCES}

Benjamin, Walter 1969 [1935]. The Work of Art in the Age of Mechanical Reproduction. In Hannah Arendt (ed). Illuminations. New York: Schocken Books.

Benson, Peter and Kirsch, Stuart 2010. Capitalism and the Politics of Resignation. Current Antbropology 51 (4): 459-486. https://doi.org/10.1086/653091.

Blaser, Mario and De la Cadena, Marisol 2018. A World of Many Worlds. Durham and London: Duke University Press.

Lassila, Maija in review Making Images to Engage with Nonhuman Worlds in a Mineral-rich Peatland in Arctic Finland. Visual Studies. In review.

Rutsky, R.L. 2007. Walter Benjamin and the Dispersion of Cinema. symplokë 15 (1-2): 8-23.

Tsai, Yen-Ling, Isabelle Carbonell, Joelle Chevrier and Tsing, Anna 2016. Golden Snail Opera. The More-Than-Human Performance of Friendly Farming on Taiwan's Lanyang Plain. Cultural Anthropology 31 (4): 520-544. https://doi.org/10.14506/ca31.4.04.

MAIJA LASSILA

PHD CANDIDATE

DEVELOPMENT STUDIES

UNIVERSITY OF HELSINKI

maija.lassila@helsinki.fi 